\title{
METASTABLE PHASES AND TRANSFORMATIONS IN THE ENGINEERING MATERIALS
}

\author{
Antal LOVAS ${ }^{*}$, Ladislav NOVAK ${ }^{* *}$ \\ *Department of Vehicles Manufacturing and Repairing, Budapest University of Technology and Economics, Bertalan L. u. 2., \\ 1111 Budapest, Hungary, \\ tel.: +361 463 1694, fax: +361 463 3467, e-mail: lovas@kgtt.bme.hu \\ ${ }^{* *}$ Department of Physics, Faculty of Electrical Engineering and Informatics, Technical University of Košice, Park Komenského 2, \\ 04200 Košice, Slovak Repubic
}

\begin{abstract}
In this paper a survey of metastabilities will be presented, which often occur in important technical materials and processes. Several metastable phases are formed during rapid cooling of liquids or solid precursors. The industrially applied mechanical alloying, leading to the formation of nano-crystalline and amorphous systems will be also treated briefly together with the metastabilities, associated with the high specific surfaces. This knowledge is useful in the appreciation of driving force of sintering process. Finally some harmful and beneficial manifestation of mechanically induced dislocation pileup will be outlined. They were observed in rolling contact or sliding friction in certain mechanical machine parts.
\end{abstract}

Keywords: rapid cooling from liquid or solid state, surface energy, sintering, dislocation pileup, crack formation

\section{INTRODUCTION}

The occurrence of thermodynamic metastability is quite common in the engineering materials [1, 2] or, even in the surrounding universe (supercooled water droplets in clouds) [3]. The existence of metastability is not restricted solely to bulk phases but also often coexists as a part of thermodynamically stable phases. Surfaces and interfaces between the equilibrium polycrystalline phases or the aggregates of small particles can also be regarded as metastable ones, because of the lack of equilibrium atomic coordination [4]. The work hardening in metals and alloys (dislocation pileup during mechanical deformation) also represents a degree of metastability. In the present paper we try to reveal some common aspects of the metastability formation, giving also some typical examples to the ceasing of the metastable state [5] (stabilization), especially in the field of technically important materials and processes including some commercial metals and alloys, as well as ceramic materials.

\subsection{Thermodynamic background}

The free-enthalpy change $(\Delta \mathrm{G}=\Delta \mathrm{H}-\mathrm{T} \Delta \mathrm{S}$, where $\mathrm{G}, \mathrm{H}$, $S$ are the free enthalpy, enthalpy and entropy, respectively) associated with the phase transformation) is used for the characterization of equilibrium and, for the prediction of direction of transformations. (see Fig. 1).

The condition of $\Delta \mathrm{G}=0$ (Fig. 1) is applied for the characterization of metastable and stable states as well. The $G_{\text {exc }}$ (excess free energy) is associated with the metastable state compared to the stable ones. Special atomic configurations (topological and chemical short range order) belong to each equilibrium. The $G_{\text {exc }}$ consists of two terms arising from chemical bonding energy between the neighbouring atoms (enthalpy term) and the entropy term, in which the configurational entropy change (topological difference) is dominant. If the chemical term $(\Delta \mathrm{H})$ is pronounced, the $\mathrm{G}_{\mathrm{exc}}$ is significant. In contrast, when the $\Delta H$ is small and $G_{\text {exc }}$ consists mainly from the entropy change (for example, transition between allotropes, in which compositional change is negligible), the total $G_{\text {exc }}$ is small.

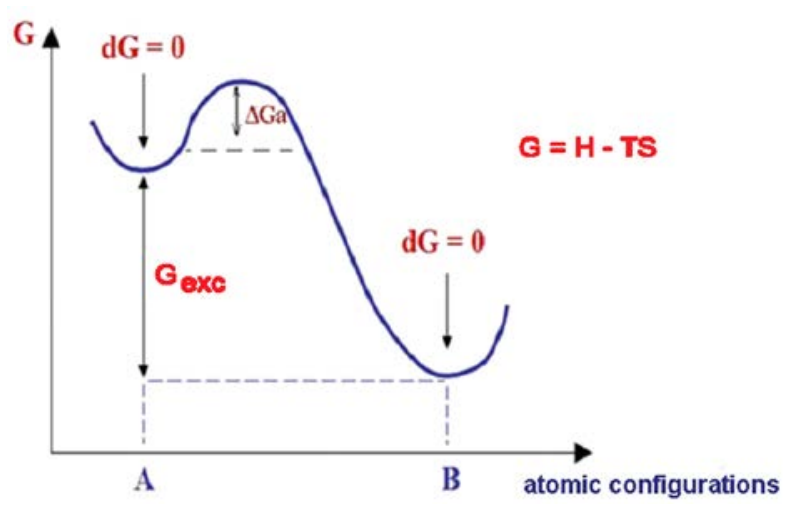

Fig. 1 The local minima of G, indicating the position of metastable and stable equilibrium associated with the appropriate atomic configurations

Another important quantity (see Fig. 1) is $\Delta \mathrm{Ga}$, associated with the energy gap (activation energy), which should exceed, for the enhance of the spontaneous transformation to the stable equilibrium (position of B).

\subsection{Kinetic approach for the metastability formation}

System-dependent characteristic times, $(\tau)$ are defined for the description of metastability formation (avoidance of thermodynamic stability) (Fig. 2).

The essence of metastable state formation is the delayed atomic rearrangement compared to the rate of the energy subtraction $(\tau)$. The time-period of $\tau_{1-2}$ is necessary for bringing the system into activated state. When $\tau_{1 \text {-a }}$ is shorter than that, for the rearrangements characteristic to $G_{2}$ (stable) state, an excess free energy will be entrapped $\left(G_{a}\right)$. The categorization of metastabilities is collected in the Table 1 . 


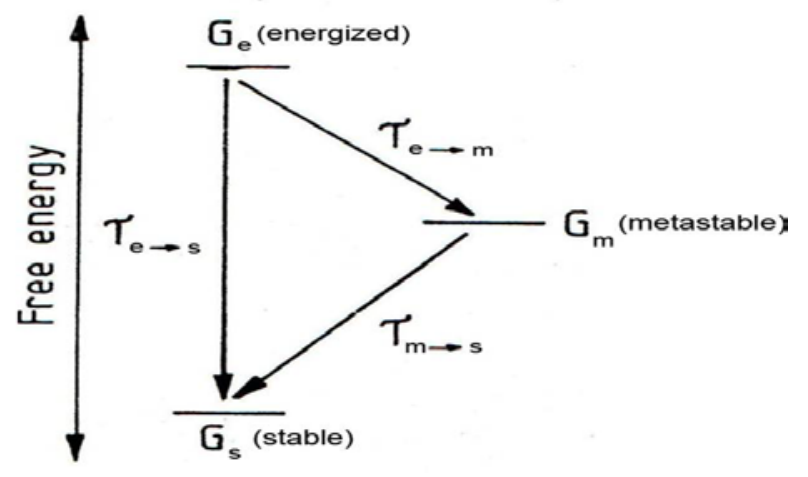

Fig. 2 chematic diagram illustrating the free energy relationships and time scales for transformation from metastable to stable state [6]

Table 1 The categorization of metastabilities based on the magnitude of $\mathrm{G}_{\text {exc }}$

\begin{tabular}{|c|c|c|c|}
\hline $\begin{array}{c}\text { Nature of } \\
\text { metastability }\end{array}$ & Examples & $\begin{array}{c}\text { Excess } \\
\text { energy } \\
\left(\mathrm{RT}_{\mathrm{m}}\right)\end{array}$ & $\begin{array}{c}\text { Excess } \\
\text { energy } \\
(\sim \mathrm{kJ} / \mathrm{mol})\end{array}$ \\
\hline COMPOSITIONAL & $\begin{array}{c}\text { Supersaturated } \\
\text { solutions }\end{array}$ & $\leq 1$ & 10 \\
\hline STRUCTURAL & $\begin{array}{c}\text { Intermetallics } \\
\text { Undercooled liquids } \\
\text { Amorphous }\end{array}$ & $\leq 0.5$ & 5 \\
\hline $\begin{array}{c}\text { MORPHOLOGICAL } \\
\text { and } \\
\text { TOPOLOGICAL }\end{array}$ & $\begin{array}{c}\text { Nanocrystall. } \\
\text { Interphase dispersion }\end{array}$ & $\leq 0.1$ & 1 \\
\hline
\end{tabular}

According to Table 1 [7], the metastabilities can be categorized on the basis of magnitude of excess free energy or, according to the nature of the involved phenomena.

The large value of $G_{\text {exc }}$ is characteristic for the supersaturated solution-type of metastabilities, which form solid or liquid phase, during rapid heat extraction (cooling). In the following section, this type of metastability will be outlined.

The similarity between the supersaturated crystalline solid solution and glassy phase formation during rapid heat extraction (kinetic similarity between the martensitic and glass transformations).

The similarity between the martensitic and glass transformation is remarkable from the point of view of their atomic level mechanism, as well as when the kinetic description is compared. Rapid heat extraction and nondiffusive transformations are included in both processes. The suppression of long range atomic diffusion is an essential feature in both cases. The common feature of the transformations can easily be recognized comparing the shape of TTT curves in the Figs 3 and 4. The initial, energized state (assigned as G1 in the Fig. 3), is a homogeneous single phase solid or liquid solution. The incubation time (time necessary for the suppression of critical nuclei formation of equilibrium phases) has a minimum around the "nose" of the curves. This systemcharacteristic time-minimum ( $\mathrm{t}_{\min }$ in Fig. 4) depends on the ability of supercooling of the phases, being stable at high temperatures. When this temperature range is exceeded, non-diffusive transformations have started in both cases. (Martensitic transformation in carbon steels, or the glass transition in liquids, see Figs 3, 4).

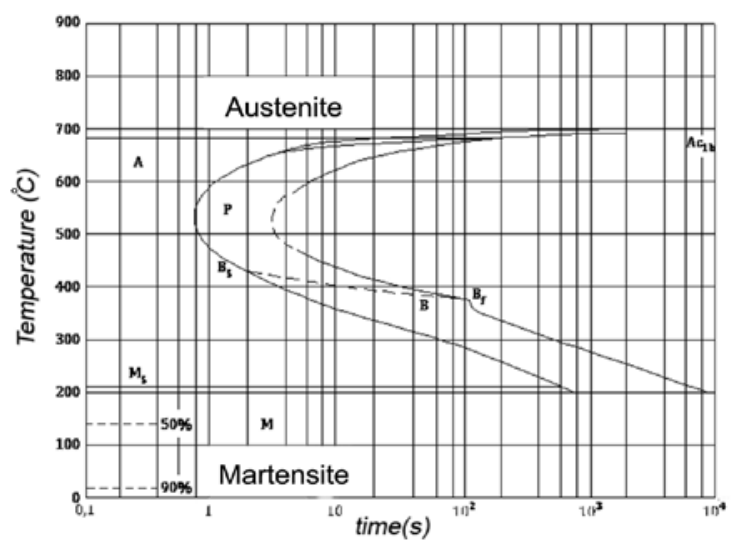

Fig. 3 The shape of TTT (time-temperature-transformation) curves in the case of martensitic transformation in $0.8 \%$ carbonsteel. $\mathrm{M}_{\mathrm{s}}$ and $\mathrm{M}_{\mathrm{f}}$ markers shows the starting and finishing temperatures of the transformations, $\mathrm{B}_{\mathrm{s}}$ and $\mathrm{B}_{\mathrm{f}}$ markers refer to the start and end for the Bainite formation respectively, $\mathrm{P}$ is the area of pearlite formation area)[3].

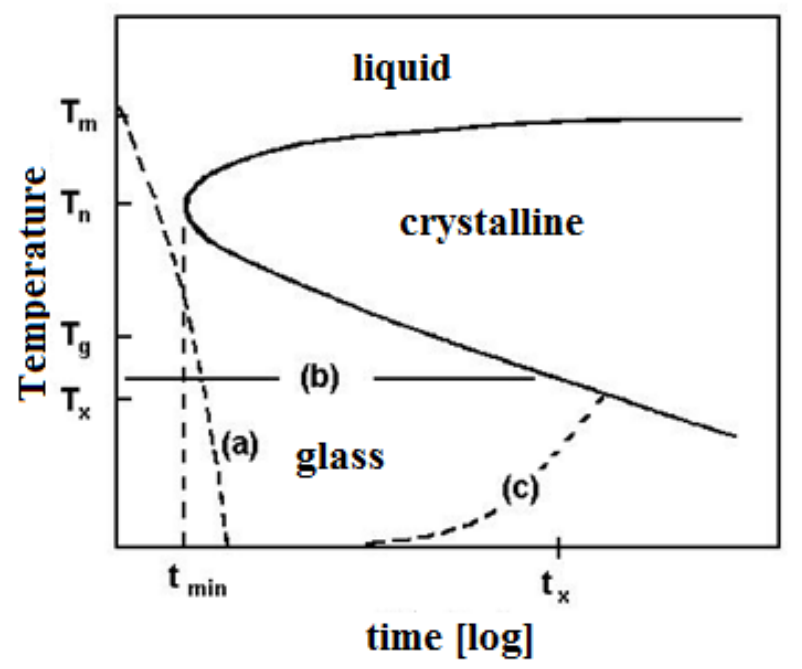

Fig. 4 The temperature-time-diagram for liquid-crystalline and liquid-glass transformations [5]

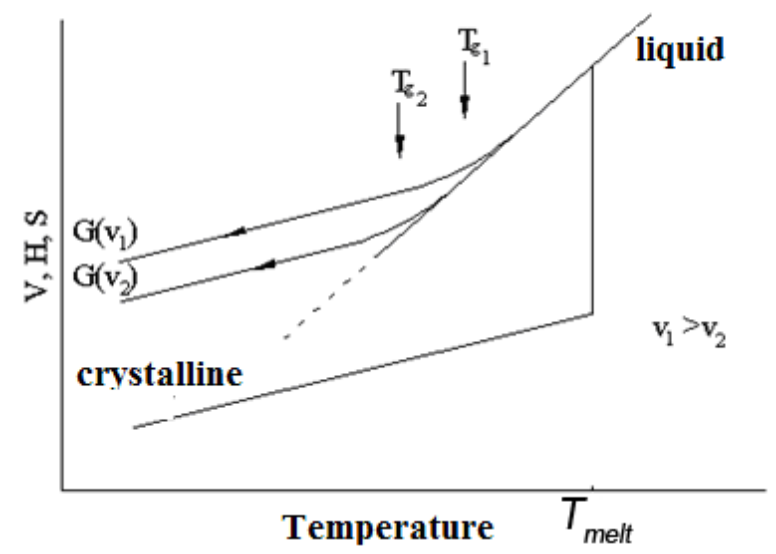

Fig. 5 The change of specific volume, enthalpy and entropy during the supercooling of a glass forming melt, which exhibit glass transition at the $\mathrm{T}_{\mathrm{g} 1}$ and $\mathrm{T}_{\mathrm{g} 2}$ depending on the applied cooling rate [1] 
The quenched-in free volume in the glass increases with the applied cooling rate according to Fig. 5. It means that the free volume can be altered along the cross section of a glassy rod-shape sample.

The density (frozen free volume) change as a source of macroscopic stress evolution in the glassy state.
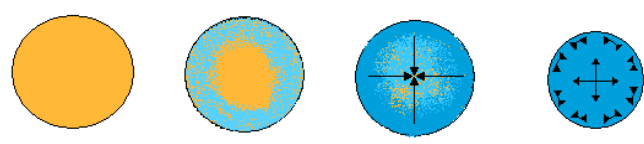

Fig. 6 The evolution of macroscopic compressive and tensile stresses in rod-shape glassy sample due to the change of radial cooling rate [8]

The cooling rate dependence of free volume has a harmful consequence in the production of rod-shape glassy samples, or in general in the glass-manufacturing. Typical example is illustrated in Fig. 6.

As a consequence, macroscopic tensile stress at the surface, and compressive stress in the centre is developed, resulting in inhomogeneous stress distribution in the sample. This inhomogeneous stress state is metastable.

Such stress-inhomogeneity can easily be detected in the "as-prepared" sample by applying polarized light transmission. The outlined metastability types are usually eliminated by appropriate relaxation heat treatments at temperatures, near the $\mathrm{T}_{\mathrm{g}}$. Similar inhomogeneous radial stress distribution is developed in the cross section of quench-hardened bulk steel work-pieces.

\subsection{Large specific surface as the source of metastability formation}

The equilibrium coordination between the constituent atoms is never fulfilled in the vicinity of surfaces, or in the region of grain boundary of the bulk poly-crystals. Thus, at least the topological metastability co-exists with the bulk phase, (i.e., as a small fraction of atoms is occupied in non-equilibrium spatial position). The importance of this metastability type is more pronounced in dispersed systems (powders, second phase precipitation and thin layers). The excess energy (decrease of specific surface) is the driving force for several engineering process, like the sintering, precipitate ripening etc. Sintering is widely applied technology of ceramic industry and in the semifinished production (decreasing of cutting vast).

The tendency of decreasing specific surface during the sintering process is illustrated in Fig. 7a, b. In Fig. 7a, the development of common interface is shown between two particles, the initial period can be observed as the appearance of neck formation between two neighbouring particles $\left(r_{n}\right.$ radii characteristic to the period of neck formation). The elimination (collapse) of pores is also an essential part of densification (shrinkages), as it is illustrated in the Fig. $7 \mathrm{~b}$.

The time and temperature dependence of the shrinkage (or the $\rho$ ) is described by semi-empirical equations (Eq. 2 ), in which $d \rho / d t$ is the rate of density change, $n$ is characteristic with the initial grain dimension, $\mathrm{Q}$ is the activation energy, and $\mathrm{C}$ is the system-specific constant.

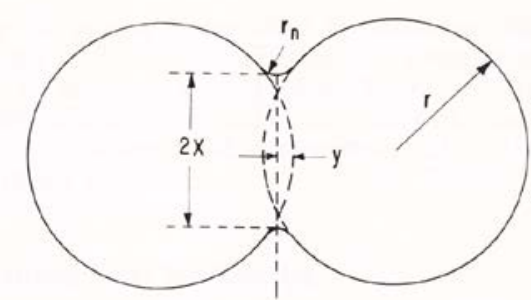

(a)

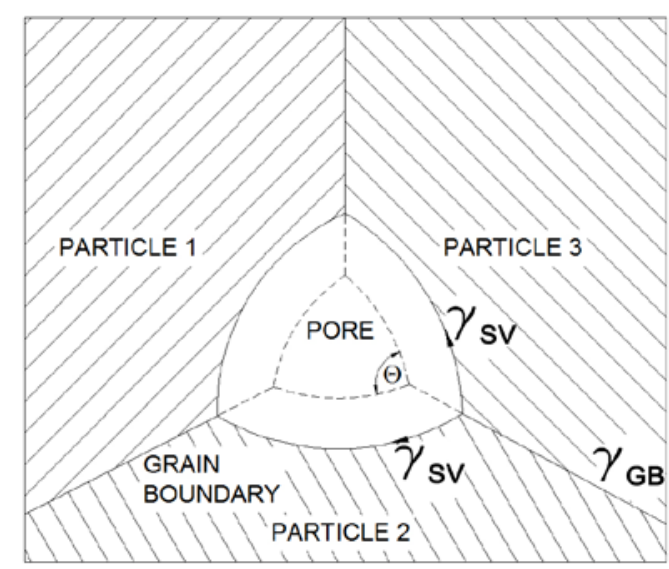

(b)

Fig. 7 a. Development of common interface between two particles in the neck-formation period [11].

b. Schematic illustration of the collapse of a pore surrounded by tree particles, simultaneously, common grain boundary is formed between the adjacent particles $\left(\gamma_{\mathrm{sv}}\right.$ solid-gas surface energy, $\gamma_{\mathrm{gb}}$, grain boundary energy)

$\frac{d \rho}{d t}=\frac{C}{a^{n}} \exp \left(\frac{-Q}{R \cdot T}\right)$

According to this equation, the sintering time (shrinkage to attain the final density value) is different for fine and coarse particles.

\subsection{Systems with ultra-large specific surfaces: the nanostructures}

The appearance of extra-ordinary properties due to the high specific surface is well known (exceptional gas absorption ability, chemical affinity, etc.)

When a critical value of atomic fraction in the vicinity of surface is exceeded, a dramatic change can be experienced even in the fundamental physical properties (which are normally attributed to the bulk state). Well known example is the melting point suppression, change of specific electrical resistance, etc). The abrupt change is typical in the nanometer-scale grain dimension, as it is shown in Fig. 8.

The presented results are a model calculation. According to the presented model, the sudden-property changes can really be expected as a consequence of the increasing fraction of non-equilibrium atomic coordination, though the results also depend on the postulated grain boundary thickness. It is important to note that the grain-size dependence is specific to the individual property (melting temperature decrease is significant in the dimension of 1-2 nm temperature range 
nanometer-scale only, because this property is directly coupled to the nature of the chemical bond and atomic coordination number.) Thus, the concept of dimension (grain size) holds a fundamental meaning in this metastability type. The essence of this concept is that the nanometer-scale dimension represents typically the limit of macroscopic properties, which are originally attributed to the classic macroscopic (bulk) phase concept. In other words, the nanometer-dimension represents the transition between the properties of individual atoms and the physical properties of macroscopic phases. This supposition is similar to the modern concept of critical nuclei formation in the liquid phase (diffuse interphase concept), admitting nanometer scale dimension for the growing (critical) nuclei [13]. Accordingly, the macroscopic, characteristic phase properties are also gradually developed within this dimensional range. Below this dimension only the thermodynamic possibility for the solid phase formation is given.

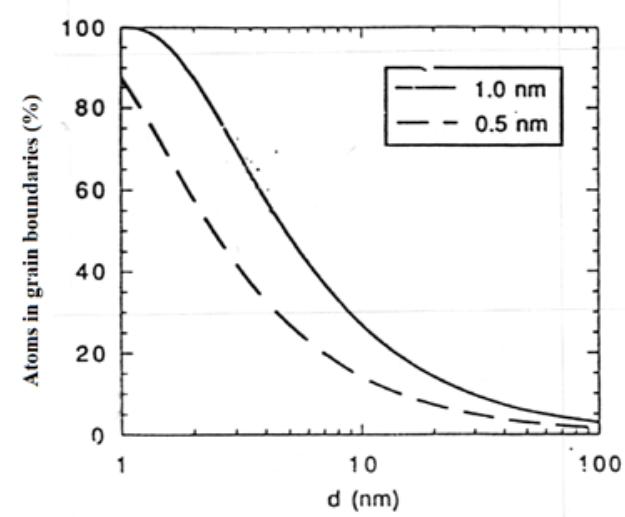

Fig. 8 The fraction of atoms in grain boundaries as a function of grain size (model calculation, supposing 0.5 or $1 \mathrm{~nm}$ wide boundary thickness) [12]

Nanocrystalline soft magnetic alloys: example for the development of size-dependent extraordinary properties

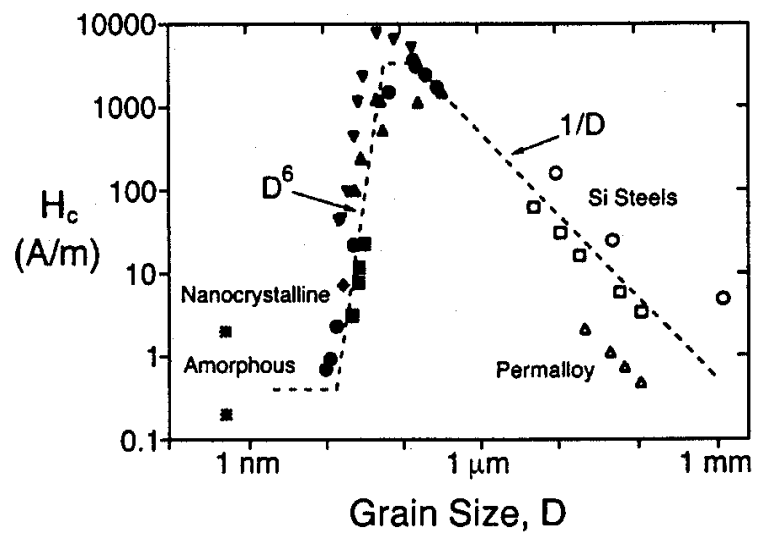

Fig. 9 The grain-size dependence of coercive force $\left(H_{c}\right)$ for several soft magnetic materials

The spectacular significance of nano-scale graindimensions in the change of coercive force $\left(\mathrm{H}_{\mathrm{c}}\right)$ is discovered in several soft magnetic alloys as it is shown in Fig. 9, where the grain size (D) dependence of coercive force in various soft magnetic materials is shown. Nearly inverse relation is fulfilled between the grain size D and $\mathrm{H}_{\mathrm{c}}$ in wide range of grain dimension (several types of alloys are included in Fig. 9!). Approaching the nanoscale region, dramatic drop of $\mathrm{H}_{\mathrm{c}}$ is observed [14].

\subsection{Metastable phase formation via mechanical alloying (MA)}

Recently, the application of mechanical alloying has outstanding significance in several non-equilibrium processing (production of nanostructural materials, dispersion-strengthened alloys, intermetallic compounds, etc.). This technology offers a unique possibility for the alloy formation from components, which are insoluble even in the liquid state; hence, the rapid quenching technique is ineffective for the metastable phase formation. Applying this method, supersaturated solid solutions can be produced from several, mutually immiscible components [15].

The effectiveness (for example the time dependence of the decreasing grain size) is influenced by several process factors, like milling time or ball to filling material ratio, atmospheric circumstances etc.)

\subsection{Mechanical stress accumulation, (beneficial and harmful consequences of plastic flow: work hardening and crack formation in structural steels}

The plastic deformation induced stress accumulation may have beneficial or harmful consequences in the engineering materials. The sub-microscopic dislocation pileup is regarded as the background of the macroscopic stress evolution and hardening, which is generally observed during the plastic deformation [16]. The aim of this process is the achievement of hardening (strengthening) of work pieces (see Fig. 10).
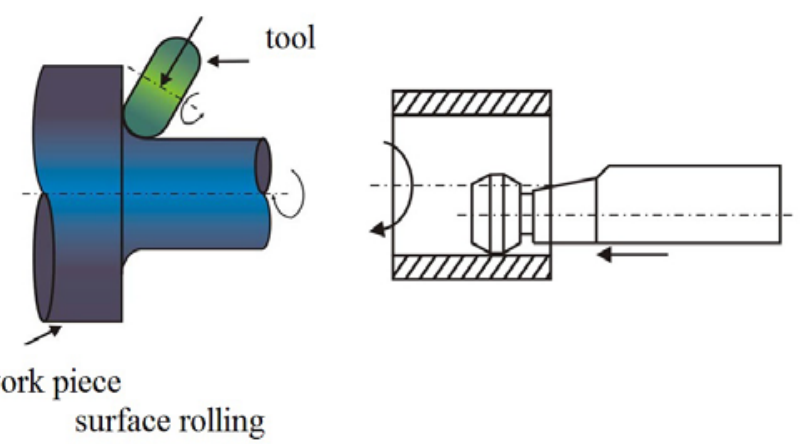

Fig. 10 Mechanical surface hardening of work pieces by applying rolling tool

An example of the harmful consequence of dislocation pile up is illustrated in Fig. 11.

The formation of macroscopic defects (cracks) near the surface of structural elements can be developed either by rolling or sliding friction processes. The importance of such surface degradation is outstanding both from the economic and safety aspects of railway traffic. For the avoidance of such macroscopic crack formation, several non-destructive investigations methods are being developed in the modern defectoscopy [17]. 


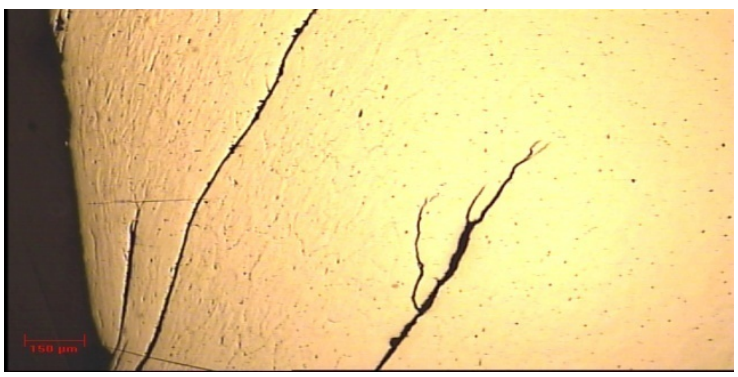

Fig. 11 Crack formation near the surface of a rail with pearlitic structure, subsequently the saturation pile up of plastic deformation induced dislocation

\section{CONCLUSIONS}

A brief survey of well-known metastabilities (phases and transformations) is presented, which are playing basic role in the engineering materials and processes.

1. Most of the metastability forms are associated with the rapid cooling of phases, being stable at high temperatures.

2. Phases with ultrahigh specific surfaces are also often used in the production processes (sintering, nanocrystalline aggregates).

3. Mechanical attrition and alloying is a powerful method for the production of supersaturated solution between immiscible components.

4. The plastic deformation induced dislocation pile up is often used for the local strengthening of work pieces (beneficial role). In contrast, dislocation accumulation may often cause harmful surface degradation, which should be avoided.

\section{ACKNOWLEDGEMENTS}

One of the authors (A.L.) acknowledges support from the scientific programme "Development of qualityoriented and harmonized $\mathrm{R}+\mathrm{D}+\mathrm{I}$ strategy and functional model at BME" project. This project is supported by the New Széchenyi Plan (Project ID: TÁMOP-4.2.1/B09/1/KMR-2010-0002).

One of the authors (L.N.) acknowledges support from the project named "Centre of Excellence for Integrated Research \& Exploitation of Advanced Materials and Technologies in Automotive Electronics”, ITMS 26220120055.

\section{REFERENCES}

[1] TAKÁCS, J.: Korszerü Technológiák a Felületi Tulajdonságok Alakításában Müegyetemi Kiadó Budapest, 2004 (ISBN 963420789 8).

[2] HORNBOGEN, E.: In R.W. Cahn and P. Haasen (Eds.) Physical Metallurgy, 3rd Edition (1983) North Holland Publishing, Amsterdam, pp. 10761138.

[3] DEBEnEDETTI, P. G.: Metastable Liquids Concepts and Principles (Princeton Univ. Press, Princeton, 1996).
[4] KAPTAY, G: Classification and general derivation of interfacial forces, acting on phases, situated in the bulk, or at the interface of other phases. J. Mater. Sci. 2005, vol. 40, pp. 2125-2131.

[5] SCOTT, M. G.: In Luborsky F. E.: Amorphous Metallic Alloys, Chapt. 10) (Butterworths Monographs in Materials) 1984.

[6] JOHNSON, W. L.: Mat. Sci. Eng. 97 (1988) 1-13 (Rapidly Quenched Metals, V. 6.1, Montreal, 1987).

[7] TURnBulL, D. - COHEN, M. H.: J. Chem. Phys. 34120 (1961).

[8] KINGERY, W. D. - BOWEN, H. K. - ULMANN, D. R.: Introduction to Ceramics, Wiley, New York, 1975.

[9] AZIZ, M. J.: J. Appl. Phys. 53 (1982) 1158.

[10] BOETTINGER, W. J - PEREPEZKO, J. H.: In Rapidly Solidified Crystalline Alloys, Ed. Das S. K., Kear B. H., Adam C. N., Proc. of TMS-AIME, Morristown, New Jersey (1985).

[11] Treatise on Solid State Chemistry, vol. 6. (Ed. N.B. Hannay) Plenum Press, 1970.

[12] GLEITER, H.: Nanostructured Materials V.6, 3-14.

[13] GRÁNÁSY, L. - HERLACH, D. M.: J. Non-Cryst. Solids 192-193, 470-473 (1995).

[14] HERZER, G.: Handbook of Magnetic Materials ed. Buschow, K.H.J. V. 10, 1997.

[15] SURYANARAYNA, C.: Non-Equilibrium Processing of Materials. Pergamon Materials Series, vol. 2, 1999 (Pergamon Press ed. R.W. Cahn).

[16] KÁLDOR, M.: Fizikai metallurgia, Műszaki Könyvkiadó, Budapest (1990).

[17] SZABÓ, A. - NOVÁK, L. - LOVAS, A.: Compositional and Stress State Factors During the Thermopower and Coercitivity Measurements in Technical Alloys, Physics of Materials, Kosice 2012.

Received November 12, 2012, accepted February 8, 2013

\section{BIOGRAPHIES}

Antal Lovas was born in 1938, graduated in 1967 at Eötvös Lorand University as a chemist. He spent a year at FORTE in Vac in 1967 but still in this year he got a new position at the Central Pisician Research Institut, Department of Solid State Physics (MTA SZFKI). He was working in the field of unstable and glassy alloy systems and got his candidate degree in 1992. From 1994 he is working at the Budapest University of Technology and Economics, Department of Transportation Engineering, where he got his PhD. degree in 1999. Research area: physical metallurgy, solid state chemical reactions, $\mathrm{H}$ absorption in metals. Member of the Hungarian Academy of Sciences, Member of the Soft Magnetic Materials International Conference Organising Committee. Chairman of the SMM14 (Balatonfüred) Soft Magnetic Maerials International Conference Organising Committee. 